\title{
Design and Perfromance Characteristics of a Portable Solar-Driven Thermoelectric Heat Pump under Thunder Bay Extreme Cold Conditions in Northwestern Ontario, Canada
}

\author{
B. I. Ismail and N. Alabdrabalnabi \\ Department of Mechanical Engineering, Lakehead University 955 Oliver Road, \\ Thunder Bay, Ontario P7B5E1, Canada
}

Received: May 2014; Accepted: 12 June 2014:

Publication: 30 July 2014

\begin{abstract}
Renewable \& alternative non-conventional green energy technologies used for heat-pumping applications have shown real merits and received renewed interest in recent years especially in small-scale portable heating applications. Solar-driven thermoelectric heat pumping is one of these innovative technologies. In this paper, a thermoelectric heat pump that utilizes the Peltier effect has been designed, constructed and instrumented for suitable experimentation and characterization under Thunder Bay city extreme cold weather conditions in Canada. The thermoelectric test setup is powered using a renewable solar photovoltaic system and tested under different operating conditions. It was found that the PV-powered thermoelectric heat pump system has shown an acceptable performance with COP ranging from 0.98-1.22. Typical results showed that the average heat pumping power for the system was $72.1 \mathrm{~W}$ when the system was operated at an ambient temperature of $-17^{\circ} \mathrm{C}$ with an inside system temperature increased from approximately $-5^{\circ} \mathrm{C}$ to $25^{\circ} \mathrm{C}$.
\end{abstract}

Keywords: Clean renewable energy, solar PV, Thermoelectric, heat pump, Thunder Bay.

Journal of Green Engineering, Vol. 4, 117-134.

doi: 10.13052/jge1904-4720.422

(c) 2014 River Publishers. All rights reserved. 


\section{B. I. Ismail et al.}

\section{Introduction}

Thermoelectric (TE) modules are solid-state heat pumps (or refrigerators in case of cooling) that utilize the Peltier effect between the junctions of two semiconductors. The TE modules require a DC power supply so that the current flows through the TE module in order to cause heat to be transferred from one side of the TE module to other, thus creating a hot and cold side. There is no intrinsic difference between a thermoelectric heat pump (TEHP) or a thermoelectric refrigerator (TER) except in terms of different utilization (depending on TE heating or cooling mode). Thermoelectric heating (or cooling) technology has received renewed interest recently due to its distinct features compared to conventional technologies, such as vapour-compression and electric heating (or cooling) systems. The attractive advantages of using TE modules in these systems and other applications (e.g. power generation, etc.) are: they have no mechanical moving parts, thus eliminating vibration and noise, and require considerably less maintenance; being environmentally friendly (no use of real refrigerants); being extremely reliable; being simple and compact; and being suited for small-scale and remote applications [1,2]. There are a number of experimental and numerical studies that characterized the performance of TE heating and cooling systems. For example, Luo, et al. [3] performed experiments and verified that a TEHP system is more efficient than an electrical heating device, for its heating coefficient reached more than 1.6 with suitable operating conditions. Their performance tests showed that the prototype can save more than $38 \%$ of the power consumption compared with that of conventional electric water heaters. Riffat and Qiu [4] compared the performance of the thermoelectric air-conditioner with two other types of domestic air-conditioners, namely the vapour compression air-conditioner and the absorption air-conditioner. In their comparison, they concluded that despite their lower coefficient of performance (COP), the thermoelectric air-conditioners have a large potential market as air conditioners for small enclosures, where the power consumption would be low, or safety and reliability would be significant. Bansal and Martin [5] investigated and compared the performance characteristics of three domestic refrigerators, namely the vapour-compression, the thermoelectric and the absorption refrigerators based on actual experimental data. In their comparison, they found that the vapour-compression system was the most efficient with an actual COP of 2.59 , followed by the thermoelectric with a COP of 0.69 and the absorption refrigerator with COP of 0.47. Bansal and Martin [5] also reported that as the TE technology has advanced, the reliability and cost of TE cooling systems 
have changed favourably and at present TE systems are available for the domestic market at comparable prices. Min and Rowe [6] investigated a number of prototype TE-coolers and evaluated their performances in terms of the COP. In their investigation [6], the COP of the TE cooler was found to be between 0.3 and 0.5 for a typical operating temperature at $5{ }^{\circ} \mathrm{C}$ with ambient at $25^{\circ} \mathrm{C}$. Riffat and $\mathrm{Ma}$ [2] reviewed research carried out to improve the $\mathrm{COP}$ of TE cooling systems. This includes the development of new TE materials, optimization of TE module design and fabrication, system analysis and heat exchange effectiveness. David at al. [7] introduced an optimization method for improving TEHP performance by operating condition management of the TE modules and design optimization the heat exchangers linked to the TE modules. Riffat et al. [8] developed a computer model to simulate the performance of a novel TEHP system incorporated in a building structure for space heating. The developed model was based on the experimental performance results obtained from a small prototype system. It was recommended that their developed model could be used as a basis for analysis and design of the TEHP system.

Renewable and clean power sources, such as solar photovoltaic (PV) can be used as an excellent source for coupling to a TEHP for heating (or TER for cooling) and similar TE systems to provide the DC current which is required for their operation. The use of a PV system as a power supply tends to make the TE technologies more attractive more particularly for small-scale applications or in remote locations where conventional sources of power are absent. Xi et al. [9] reported the benefits of using solar-based TE technologies and their applications. The application areas described in their work showed that solar-TE technologies could be used in a wide variety of fields, such as refrigeration, air-conditioning applications and power generation, and can meet demand for energy conservation and environment protection. For example, Dai et al. [10] conducted an experimental investigation on a portable solar-TE refrigerator for small-scale remote applications or in areas where electric supply is unavailable. Their results showed that the unit can maintain the inside temperature at $5-10{ }^{\circ} \mathrm{C}$, and have a COP of approximately 0.3. Le Pierrès et al. [11] performed numerical simulation to investigate the direct coupling of TE modules (cooling or heating mode) with photovoltaic (PV) cells under conditions of Chambèry, Alpine region in France. Their results showed that for the considered conditions, TE module performances are of the same order as the ones of the vapourcompression heat pumps, with a TE coefficient of performance higher than 2 for low values of input DC current. Their results also showed that the 
PV-TE coupling efficiency varies between 0.096 and 0.23 over the year, with an average value of 0.157 . They concluded the possible use of solarpowered TE modules for ventilation air pre-heating and pre-cooling in housing. Atik and Yildiz [12] perfromed experimental tests and investigation on a domestic type TE cooling system that is powered by PV cells. Their results showed that the COP of the operated PV-TE cooler was approximately 0.58 . Abdul-Wahab et al. [13] tested a portable PV-TE refrigerator for remote applications and found that the COP of their system was approximately 0.16 under the conditions of their tests. In this paper, a TEHP system that utilizes the Peltier effect has been designed, constructed and instrumented for suitable experimentation and detailed characterization under Thunder Bay city extreme cold weather conditions in Northwestern Ontario, Canada. A solar PV system is used to provide the DC power for the TEHP test setup (thus called PV-TEHP). The following sections describe the main components and design aspects of the PV-TEHP system, the experimental procedure used in the study and the characterization and discussion of its performance. The PV-TEHP is proposed for use to preserve the heat of foodstuffs kept in the TEHP unit operating under cold climate. It should be noted that this paper is an extended version of the presented paper in ICANM 2013.

\section{Test Site Meterogical Environment}

The detailed experimental heating tests using the PV-TEHP system were performed under Thunder Bay climatic conditions in a typical winter season. Thunder Bay city $\left(48^{\circ} 24^{\prime} \mathrm{N}, 89^{\circ} 14^{\prime} \mathrm{W}\right)$ is located on the northwestern shore of Lake Superior. The climate in the Thunder Bay area is typical of a mid-latitude inland location with a lake moderating influence. The winter season in Thunder Bay lasts approximately 6 months extending from November to May and is characterized by very cold temperatures (in January 2013, the coldest temperature reached as low as $-36.3{ }^{\circ} \mathrm{C}$ and $-41{ }^{\circ} \mathrm{C}$ considering wind chill factor ([14]) and relatively high incidence of sunshine. The coldest months typically occur in January and February with a typical average daily high in January of approximately $-9{ }^{\circ} \mathrm{C}$.

\section{Design of the PV-TEHP}

A schematic diagram of the PV-TEHP test setup used in this investigation is shown in Figure 1 and its photograph is shown in Figure 2. As shown in Figure 1, the PV-TEHP system mainly consists of the heat pump equipped 


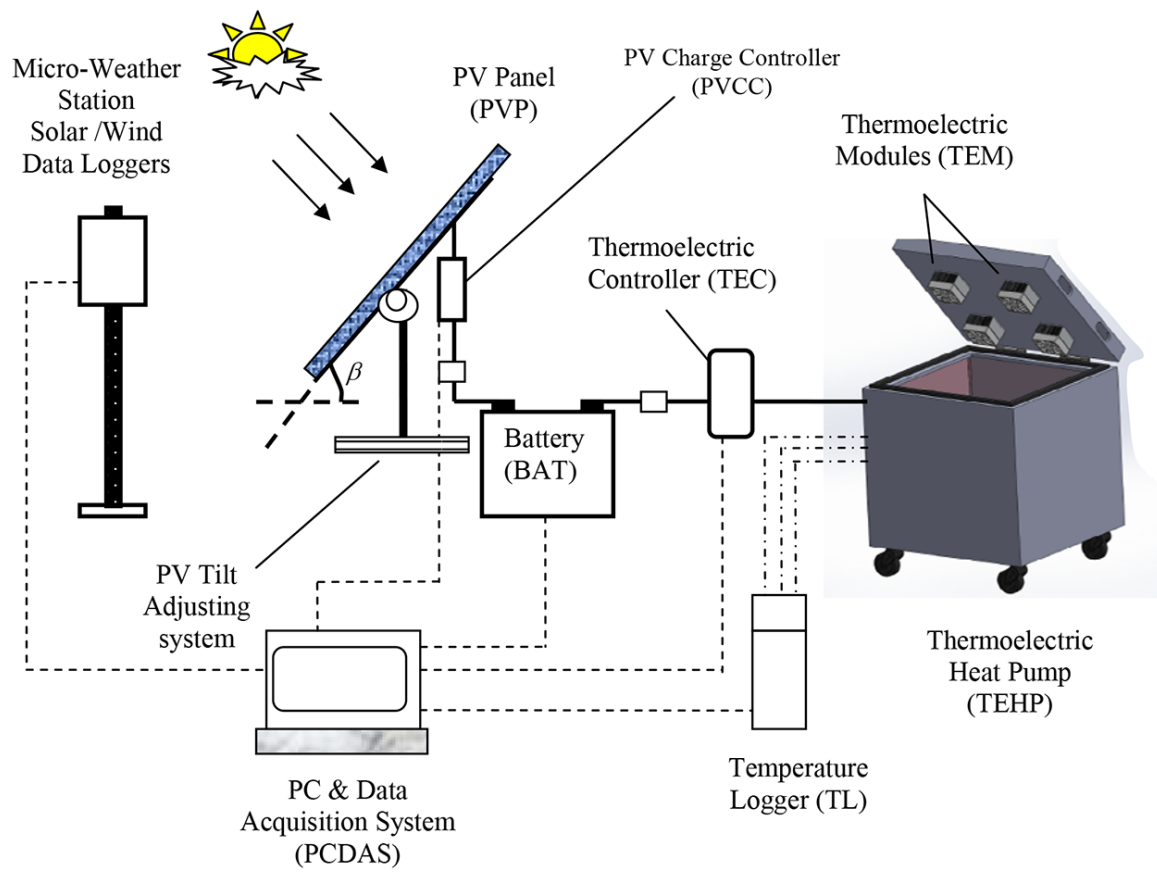

Figure 1 A schematic diagram showing the main components and connections of the PV-TEHP system test setup used in this investigation ( $\beta$ is the tilt angle of the PVP)

with TE modules with heat sinks and fans, a 120-W PV panel with area of approximately $1 \mathrm{~m}^{2}$ used to provide the DC power to operate the TEHP, a deep-cycle battery bank for energy storage, a charge controller to maintain optimal performance of the battery for longer operation life, and a TE temperature controller to control the heating capacity of the TEHP system. The TEHP unit is made of aluminium and has inside and outside volumes of approximately $0.064 \mathrm{~m}^{3}$ and $0.1264 \mathrm{~m}^{3}$, respectively.

Foam insulations are properly installed in the TEHP unit in order to reduce inevitable heat losses to the outside ambient air. The PV panel is installed on a tilt adjusting system to provide support structure and accurate mechanism for controlling the tilt angle of the panel. The PV-TEHP system was fully instrumented in order to provide the performance characteristics of the system at different operating conditions. This includes a micro-weather station equipped with solar radiation and wind speed sensors and data loggers (HOBO model), eight K-type thermocouples for temperature measurement at 


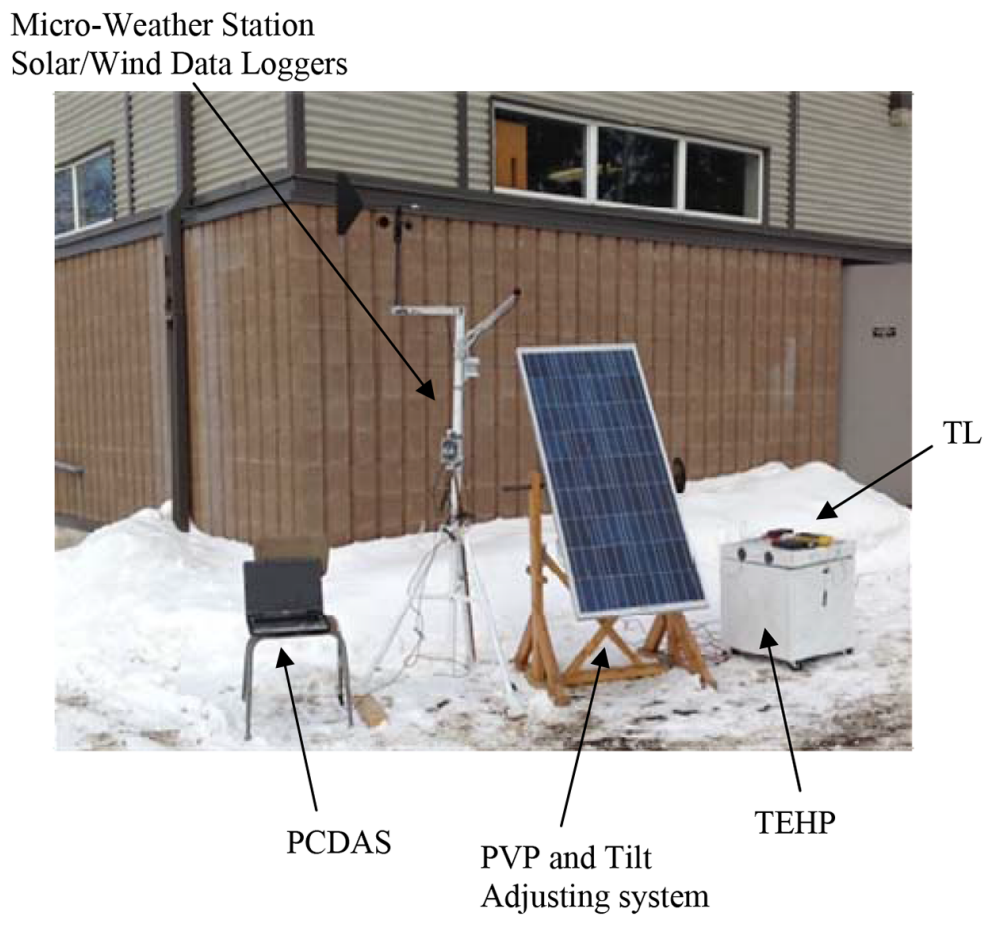

Figure 2 Photograph of the PV-TEHP test setup located in the outdoor for experimentation

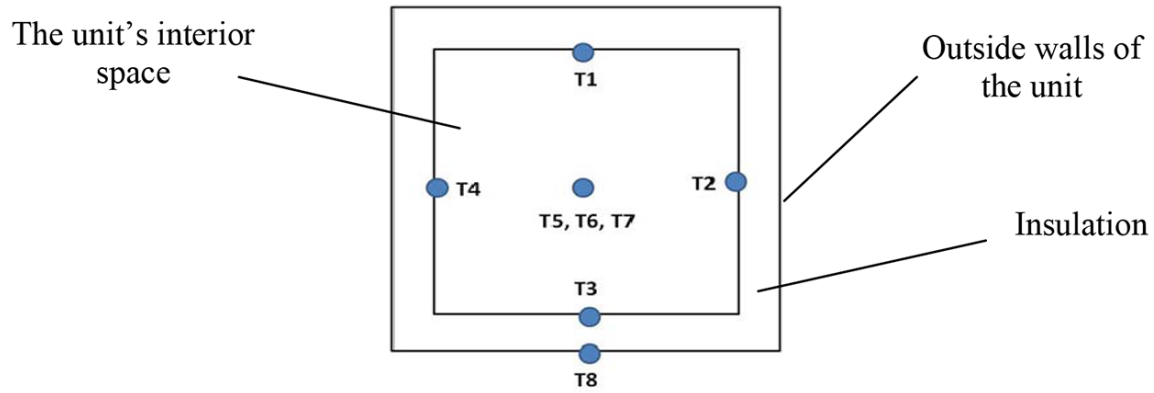

Figure 3 Locations of the installed thermocouples in the TEHP unit (top view)

various locations in the TEHP unit (see Figure 3) to measure the temperature distribution in the unit, digital temperature data loggers, voltage and current measuring devices with data loggers, and a portable computer with data acquisition system. 


\section{Experimental Procedure}

Experimental tests and measurements were performed to characterize the performance of the PV-TEHP under the outdoors of Thunder Bay winter climatic conditions. Seven tests (representing five cases) for seven days were performed in atypical cold month in a winter season to demonstrate the typical performance of the PV-TEHP. Table 1 summarizes the conditions of each case. The tests started around 10:00 am and measurements were taken every 10 minutes time interval for approximately 4 hours.

In the first case, two tests were performed in two different days (termed Day 1 and Day 2) on which the PVP was tilted at an angle $\beta$ equal to the latitude $\phi$ of Thunder Bay. In this case, the TEHP unit was empty in order to study the performance characteristics of the system under no load conditions. Tests were repeated but under load conditions (a container filled with $500 \mathrm{ml}$ of water is placed in the unit) in days 3 and 4 (case 2). In cases 3 and 4, the conditions are similar to case 1 except that the PVP was tilted at half of the latitude (case 3), and at a horizontal plane with respect to the reference ground surface (case 4). For the first four cases in Table 1, the whole PV-TEHP was operated including the battery. However, case 5 represents the operation of the system without battery in order to study the effect of direct coupling of the TEHP to the PVP on the system performance. For all five cases the PVP was oriented directly due south of the Equator (surface azimuth angle equal zero as an optimum PVP orientation). The COP of the TEHP unit is calculated using

$$
(C O P)_{T E H P}=\frac{Q_{H P}}{P_{H P}}
$$

Where, $Q_{H P}$ is the rate of heat supplied by the TE module in the TEHP unit given by

Table 1 Summary of the conducted tests conditions

\begin{tabular}{lll}
\hline Test \# (Day) & Case \# & Conditions \\
\hline 1 & 1 & PVP is tilted at $\beta=\phi$ TEHP empty (no load) - with battery \\
2 & 1 & PVP is tilted at $\beta=\phi$ TEHP empty (no load) - with battery \\
3 & 2 & PVP is tilted at $\beta=\phi$ TEHP filled (with load) - with battery \\
4 & 2 & PVP is tilted at $\beta=\phi$ TEHP filled (with load) - with battery \\
5 & 3 & PVP is tilted at $\beta=\phi / 2$ TEHP empty (no load) - with battery \\
6 & 4 & PVP is tilted at $\beta=0$ TEHP empty (no load) - with battery \\
7 & 5 & PVP is tilted at $\beta=\phi$ TEHP empty (no load) - No battery \\
\hline
\end{tabular}




$$
Q_{H P}=4\left[\frac{T_{b}-T_{f}}{R_{t o t}}\right]
$$

Where, $T_{b}$ and $T_{f}$ are the measured temperatures on both surfaces of the TE module and $R_{t o t}$ is the total thermal resistance across the heat sink for each module (total 4 modules). The $P_{H P}$ is the power consumed (input) to the TEHP unit given by

$$
P_{H P}=I . V
$$

Where, $I$ and $V$ are the DC current and voltage supplied to the TEHP unit.

\section{Results and Discussion}

Typical results of the variation of temperatures in the TEHP unit with time for case 1 are shown in Figures 4 and 5. For both tests, the temperature distribution of the space inside the TEHP unit $\left(\mathrm{T}_{1}\right.$ to $\left.\mathrm{T}_{7}\right)$ look uniform and consistent as their values are close at all times of carrying out the tests.

In the beginning of test 1 , the TEHP temperatures started at approximately $-5^{\circ} \mathrm{C}$ and then increased rapidly in the first hour until they reached approximately $15{ }^{\circ} \mathrm{C}$. The temperatures then increased slowly in the next hour until they hit around $20{ }^{\circ} \mathrm{C}$ after which they dropped slightly and then increased

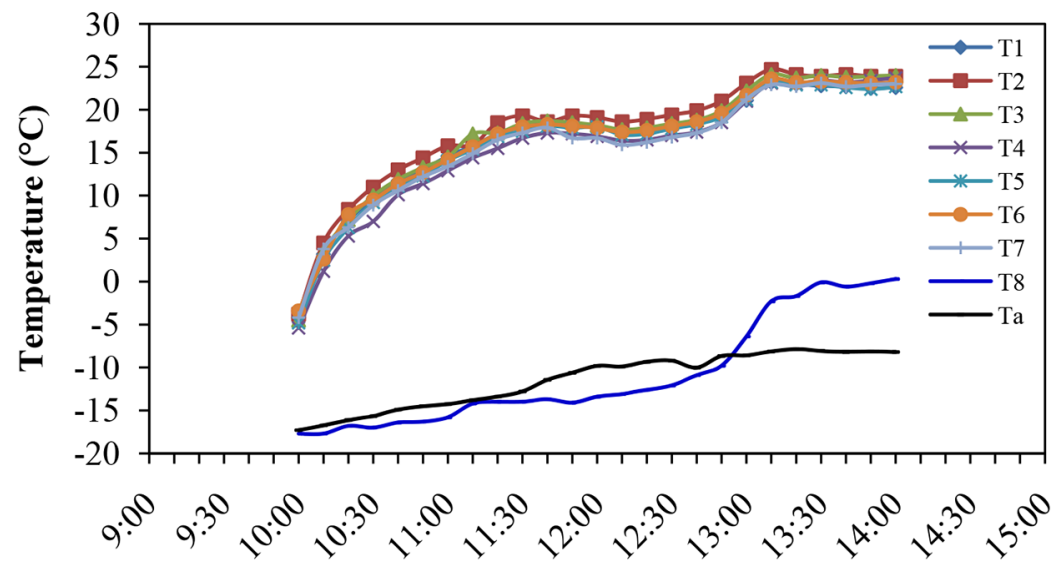

Time of day (hour)

Figure 4 Temperature variation with time of day for case 1 (test/day \#1) 


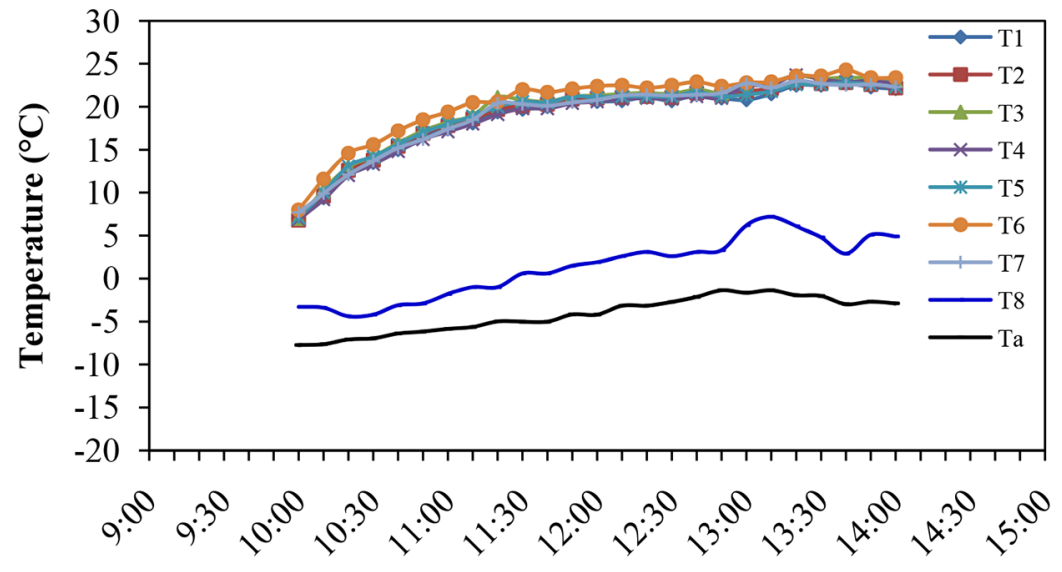

Time of day (hour)

Figure 5 Temperature variation with time of day for case 1 (test/day \#2)

again till they reached a maximum steady temperature of approximately $25^{\circ} \mathrm{C}$ at the end of this test. The reason for the slight decrease in thebreak temperature might be due to the effect of less efficient performance of the hot side of the TE modules (as shall be seen in the heat pumping $\mathrm{QHP}_{\text {HP }}$ profile during that hour). The outdoor ambient temperature $\left(\mathrm{T}_{\mathrm{a}}\right)$ was approximately $-17^{\circ} \mathrm{C}$ in the morning at the start of the test and then increased slowly until it reached around $-9^{\circ} \mathrm{C}$ at the end of test 1 .

The day on which test 2 was conducted looks relatively a bit warmer than day 1 with initial ambient temperature of approximately $-7{ }^{\circ} \mathrm{C}$. The ambient temperature then increased gradually until it reached around $-2{ }^{\circ} \mathrm{C}$ and then slightl decreased to $-5^{\circ} \mathrm{C}$ at the end of test 2 . The trend of the TEHP temperatures look smoother compared to that of test 1 with initial temperatures around $7{ }^{\circ} \mathrm{C}$ after which the temperatures increased slowly and smoothly until they became almost asymptotic having a value of approximately $25^{\circ} \mathrm{C}$.

The wind speed variation with time of day for case 1 (days/tests $1 \& 2$ ) is shown in Figure 6. The wind speed varied during the test duration between approximately 0.2 to $0.9 \mathrm{~m} / \mathrm{s}$ for test 1 , whereas it showed more fluctuation between 0 and $1.9 \mathrm{~m} / \mathrm{s}$ for test 2 exhibiting relatively more windy conditions.

The heat pumping capacity, $\mathrm{Q}_{\mathrm{HP}}$, of the TEHP unit for tests 1 and 2 is shown in Figure 7. As shown in Figure 7, test 1 demonstrated a relatively higher and steadier heat pumping of the unit during almost the entire duration of test 1 than that occurred for test 2, despite the fact that the 


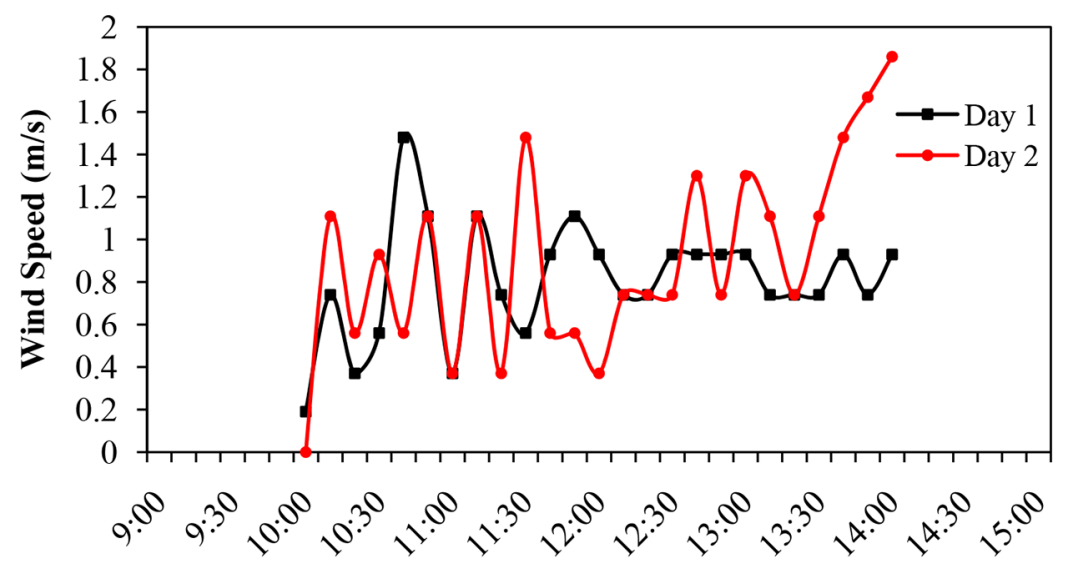

Time of day (hour)

Figure 6 The variation of wind speed versus time of day for case 1 (test/day \#1 \& 2)

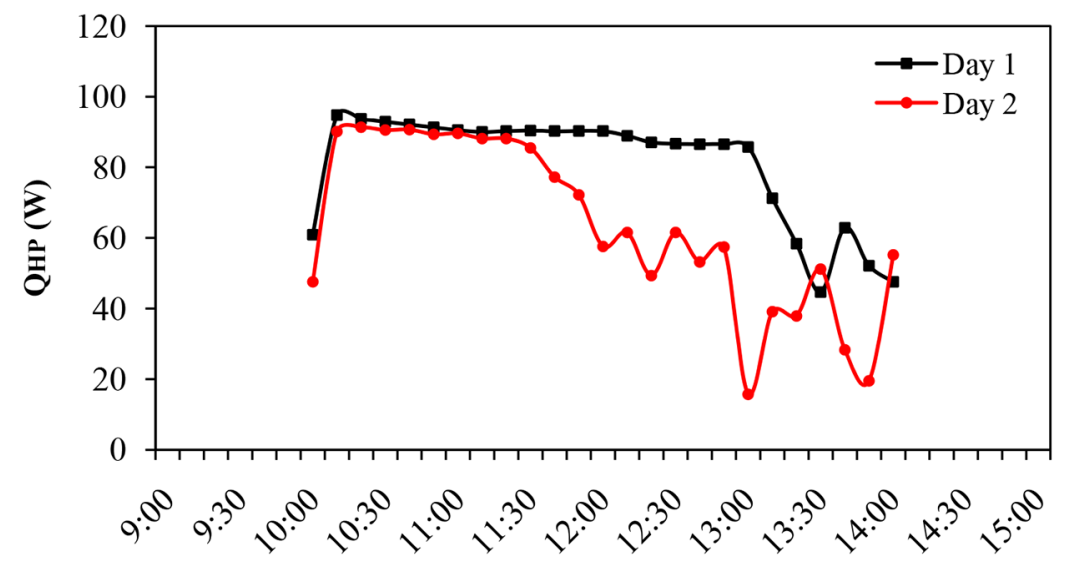

Time of day (hour)

Figure 7 The variation of heat pumping capacity of the TEHP unit versus time of day for case 1 (test/day \#1 \& 2)

day on which test 1 was conducted was much colder than that on day of test 2 . While the average heat pumping for test 1 was approximately $80.64 \mathrm{~W}$, the average heat pumping was observed to be lower at around 63.51 $\mathrm{W}$ for test 2. The kink in the $\mathrm{Q}_{\mathrm{HP}}$ profile for test 1 (sudden drop in the hour between approximately 1:00 pm and 2:00 pm might 
explain the drop in the TEHP temperatures that was observed earlier in Figure 4.

The transient solar incident power and output power provided by the PVP were compared in Figures 8 and 9 for tests $1 \& 2$, respectively.

Both power profiles demonstrated consistent behaviour for both tests 1 and 2. The highest solar power received on the PVP for test 1 was observed around noon time with a value approximately $1120 \mathrm{~W}$ (with $\mathrm{P}_{\mathrm{PV}}$ of approximately $60 \mathrm{~W}$ ), whereas for test 2 it was less around $1030 \mathrm{~W}$

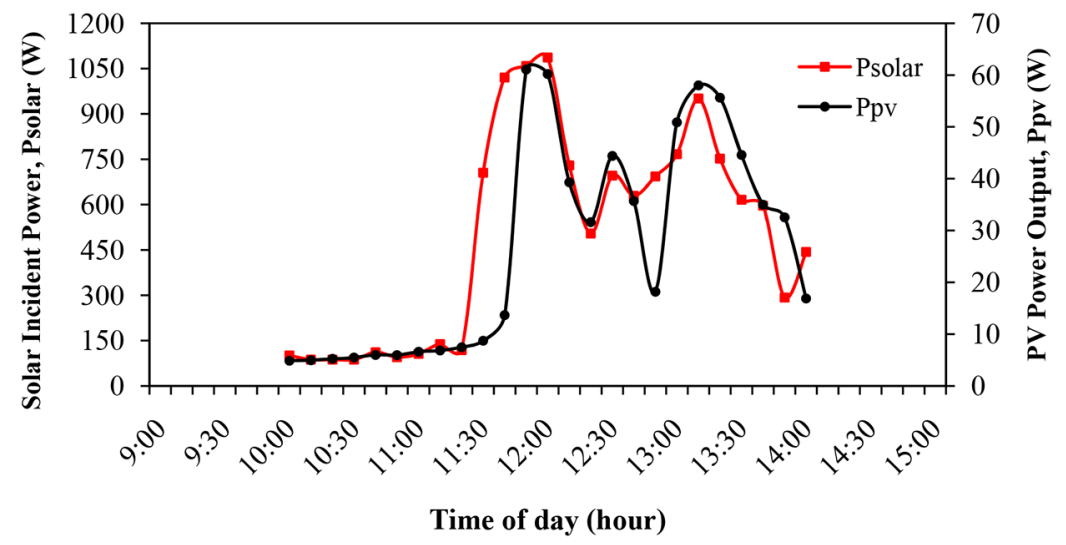

Figure 8 The variation of solar incident power and PV power output versus time of day for case 1 (test/day \#1)

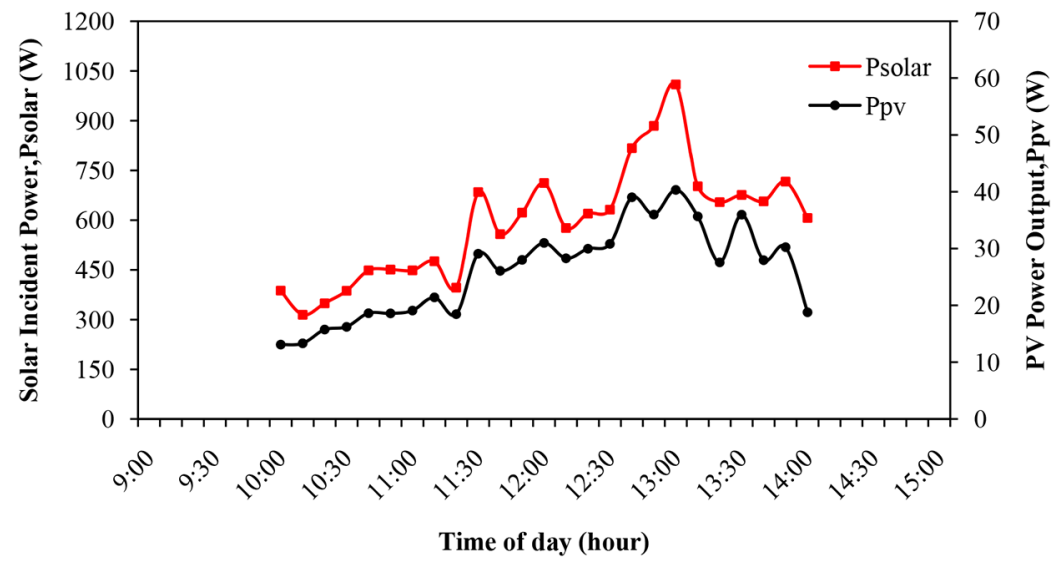

Figure 9 The variation of solar incident power and PV power output versus time of day for case 1 (test/day \#2) 
(with $\mathrm{P}_{\mathrm{PV}}$ of approximately $40 \mathrm{~W}$ ) at approximately 1:00 pm. The fluctuation in the solar insolation values was observed as a result of the sporadic cloudy conditions at different times during running these tests. The PVP efficiency (ratio of $\mathrm{P}_{\mathrm{PV}}$ to $\mathrm{P}_{\text {solar }}$ ) was calculated and demonstrated in Figure 10.

The conversion efficiency varied between 3 and $15 \%$ with an average value of approximately 9\%. The COP of the TEHP system is compared in Figure 11.

During test 1 , the COP showed more stable value of approximately 1.0 around most of the test duration time, whereas it showed more fluctuations between 0.4 and 1.2 for test 2 . The average COP for both tests was calculated to be at approximately 0.983 . Figure 12 compares the COP profiles for cases 1,3 , and 4 depending on the tilt angle of the PVP. The overall average COP of the TEHP system was found to be approximately at 1.1. The tests conducted for cases 3 and 4 (tests $5 \& 6$ ) showed more steadiness profiles compared to that of case 1 . This is likely due to the more consistent heat pumping and power consumption by the system during these tests.

The TEHP system was also tested (case 2, tests $3 \& 4$ - see Table 1) under thermal loading with placing a container filled with $500 \mathrm{ml}$ of water inside the system. Figure 13 shows the variation of the COP of the TEHP system with time of day for this case. In these tests, the COP varied between

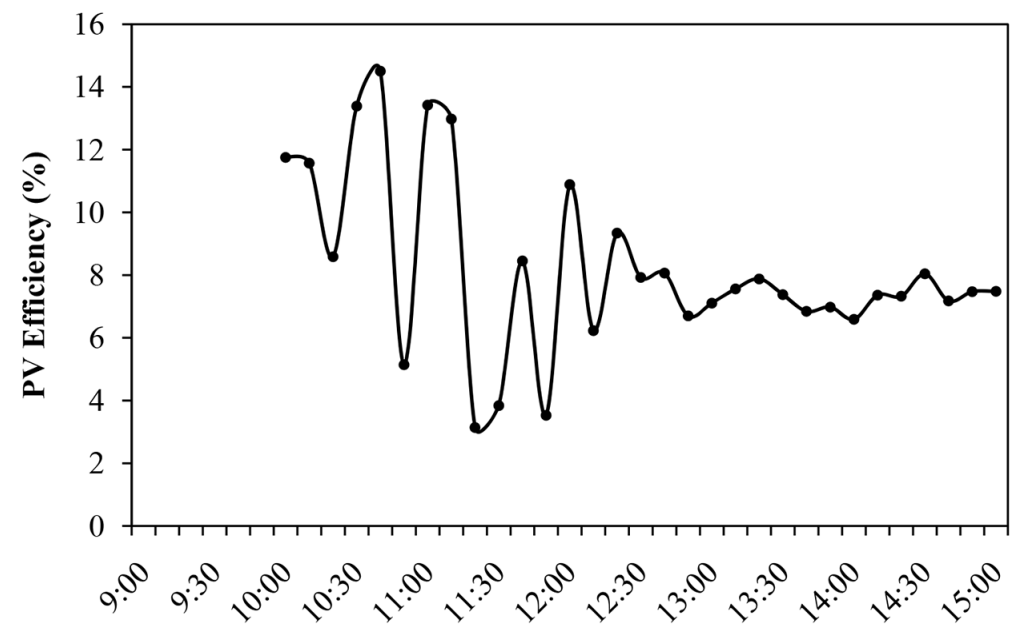

Time of day (hour)

Figure 10 The variation of PVP conversion efficiency versus time of day as calculated based on case 4 (horizontal tilt) 


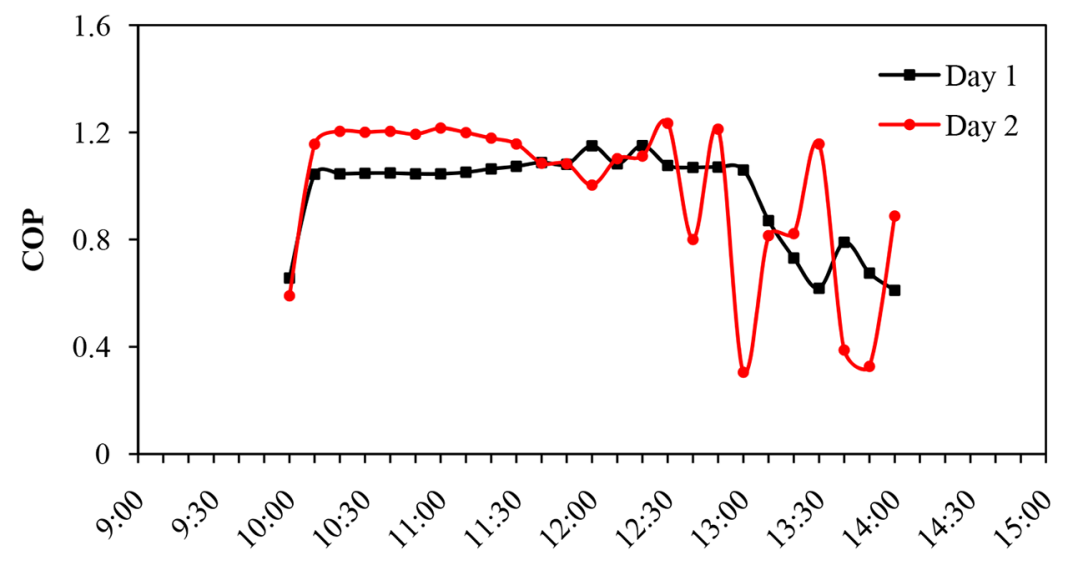

Time of day (hour)

Figure 11 The variation of $(\mathrm{COP})_{\mathrm{TEHP}}$ versus time of day (case 1 , tests $1 \& 2$ )

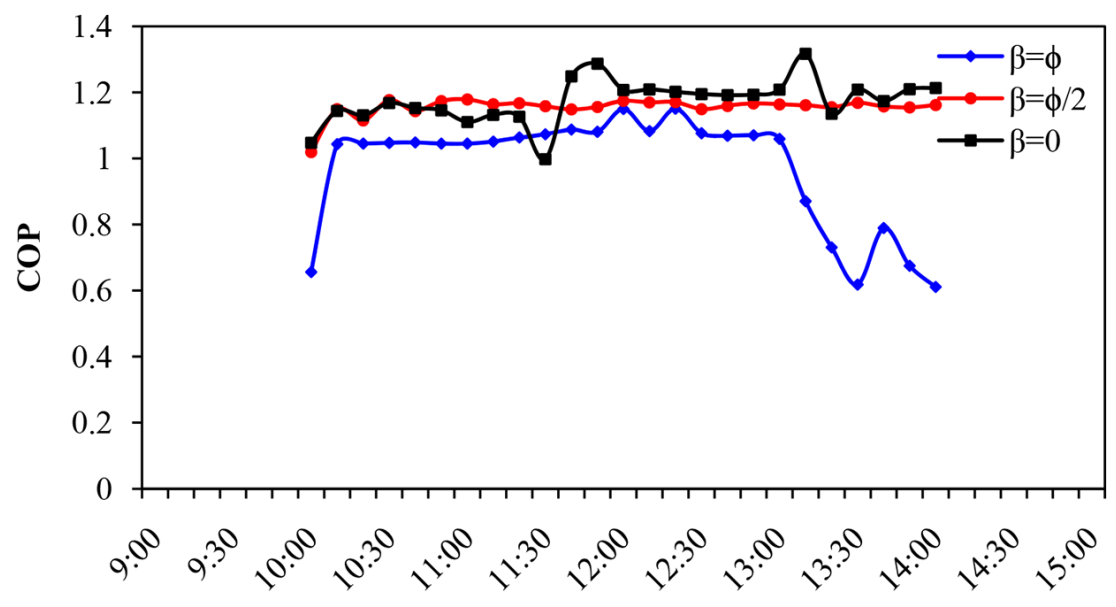

Time of day (hour)

Figure 12 The variation of (COP) $)_{\text {TEHP }}$ versus time of day (case studies 1,3-4)

approximately 0.7 and 1.5 for test 3 , whereas it varied between around 1.0 and 1.8 for test 4 . The overall average of the COP for this case was calculated to be approximately 1.217 .

Typical temperature profiles of the TEHP system is shown in Figure 14. In this figure, $T_{5}$ represents the load (water) temperature inside the system. 


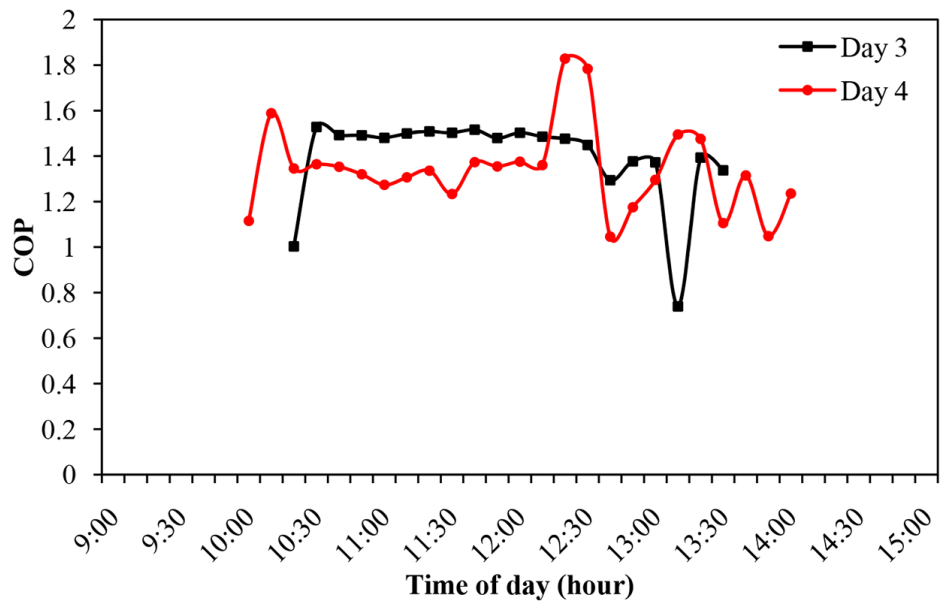

Figure 13 The variation of $(\mathrm{COP})_{\text {TEHP }}$ versus time of day (case 2, the system under loading conditions)

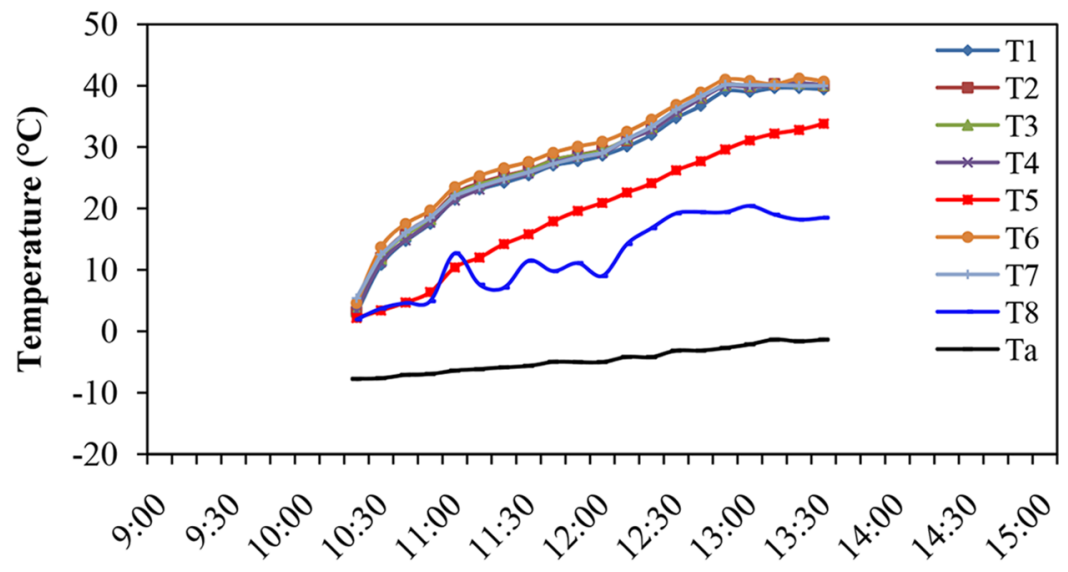

Time of day (hour)

Figure 14 The variation of TEHP temperatures versus time of day (case 2, the system under loading conditions)

The load temperature increased steadily from around $0{ }^{\circ} \mathrm{C}$ to approximately $35^{\circ} \mathrm{C}$ at the end of the test.

The effect of direct coupling of the PVP with the TEHP without battery (case 5, test 7-see Table 1) was also investigated. Typical temperature profiles of the TEHP system is shown in Figure 15. In this case, the system showed 


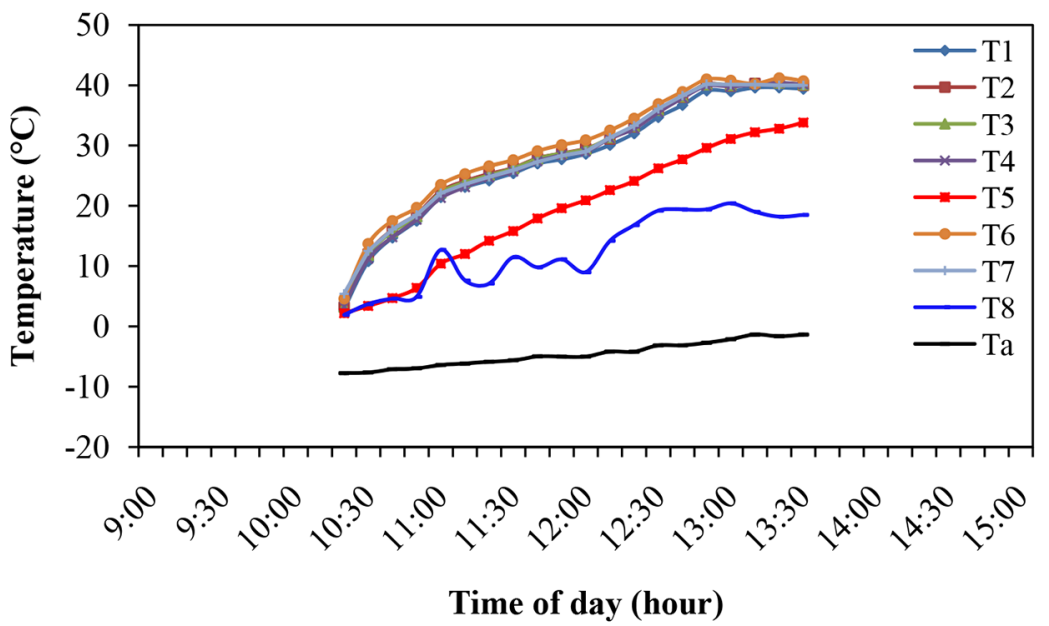

Figure 15 The variation of TEHP temperatures versus time of day (case 5, no battery)

slow response with increase in the system temperature of only approximately $8{ }^{\circ} \mathrm{C}$. This is due to the relatively lower DC electric current reaching the TEHP system directly from the PVP as compared to that provided by the battery-connected TEHP showed earlier for the other cases.

\section{Conclusions}

In this paper, a PV-TEHP system that utilizes the thermoelectric Peltier effect and a solar PV DC power has been designed, constructed and experimentally tested during daytime for six days representing four different cases under outdoors of Thunder Bay's extreme cold weather conditions in Northwestern Ontario, Canada. For case 1, two tests (for two days) were performed on the PV-TEHP system with no internal loading (inside of the TEHP system was empty) and the results showed that the overall average of the COP of the TEHP system was approximately 0.983 . However, for cases 3 and 4 with PVP tilt angle set at half of latitude angle of Thunder Bay and $0^{\circ}$, respectively, the overall average COP of the TEHP system was found to be approximately at 1.1 (with only an increase of approximately $12 \%$ compared to that of case 1 ). The system was also tested (case 2 , days 3 and 4) under loading by placing a container filled with $500 \mathrm{ml}$ of water inside the TEHP system. It was found that the overall average of the COP of the system for this case was approximately 1.217. The PV-TEHP system was also characterized in terms 
of its heat pumping power capacity. Typical results of case 1 showed that the average heat pumping power for the TEHP system was approximately 72.1 $\mathrm{W}$ when the system was operated at an ambient temperature of $-17^{\circ} \mathrm{C}$ with an inside TEHP temperature increased from approximately $-5{ }^{\circ} \mathrm{C}$ to $25^{\circ} \mathrm{C}$ within four hours of continuous system operation. It was concluded that the PV-TEHP system has shown an acceptable performance with COP ranging from $0.98-1.22$. The practical implications of this technology show promising results and usefulness for use in small-scale portable heating applications (such as preserving warm foodstuffs while camping in outdoors cold climate) or in remote locations where power supply and conventional heating technologies are absent. It should be noted that the competitiveness of this technology with other heating technologies hinges on improving the COP of these systems. This may include finding more efficient TE modules in the future research and development of TE materials as well as finding more efficient PV materials for higher energy conversion efficiency.

\section{Acknowledgements}

The main author wishes to acknowledge the funding contributions provided partly by Goldcorp Canada Ltd.-Musslewhite Gold Mine and NSERC in the area of clean renewable energy \& GHG emissions control technologies. Acknowledgement also goes to M. Akbari, R. Ewing, and T. Bown for their contributions in the construction phase of this project and to J. Bujold, B. Fischer, M. Skaf, and J. Hansen for their help in the testing phase of the project.

\section{References}

[1] Ismail, B. I., Ahmed, W. (2009). Thermoelectric Power Generation using Waste-Heat Energy as an Alternative Green Technology. Recent Patents on Electrical Engineering, 2(1), 27-39.

[2] Riffat, S. B., Ma, X. (2004). Improving the Coefficient of Performance of Thermoelectric Cooling Systems: a Review. International Journal of Energy Research, 28, 753-768.

[3] Luo, Q., Tang, G., Liu, Z., Wang, J. (2005). A Novel Water Heater Integrating Thermoelectric Heat Pump with Separating Thermosiphon. Applied Thermal Engineering, 25, 2193-2203.

[4] Riffat, S. B., Qiu, G. (2004). Comparative Investigation of Thermoelectric Air-Conditioners versus Vapour Compression and Absorption Air-Conditioners. Applied Thermal Engineering, 24, 1979-1993. 
[5] Bansal, P. K., Martin, A. (2000). Comparative Study of Vapour Compression, Thermoelectric and Absorption Refrigerators. International Journal of Energy Research, 24, 93-107.

[6] Min, G., Rowe, D. M. (2006). Experimental Evaluation of Prototype Thermoelectric Domestic-Refrigerators. Applied Energy, 83, 133-152.

[7] David, B., Ramousse, J., Luo, L. (2012). Optimization of Thermoelectric Heat Pumps by Operating Condition Management and Heat Exchanger Design. Energy Conversion and Management, 60, 125-133.

[8] Riffat, S. B., Ma, X, Wilson, R. (2006). Performance Simulation and Experimental Testing of a Novel Thermoelectric Heat Pump System. Applied Thermal Engineering, 26, 494-501.

[9] Xi, H., Luo, L., Fraisse, G. (2007). Development and Applications of Solar-Based Thermoelectric Technologies. Renewable and Sustainable Energy Reviews, 11, 923-936.

[10] Dai, Y. J., Wang, R. Z., Ni, L. (2003). Experimental Investigation on a Thermoelectric Refrigerator Driven by Solar Cells. Renewable Energy, 28, 949-959.

[11] Le Pierrès, N., Cosnier, M., Luo, L., Fraisse, G. (2008). Coupling of Thermoelectric Modules with a Photovoltaic Panel for Air Pre-Heating and Pre-Cooling Application; an Annual Simulation. International Journal of Energy Research, 32, 1316-1328.

[12] Atik, K., Yildiz, Y. (2012). An Experimental Investigation of a Domestic Type Solar TE Cooler. Energy Sources, 34, 645-653.

[13] Abdul-Wahab, S., Elkamel, A., Al-Damkhi, A., Al-Habsi, I., Al-Rubai'ey, H., Al-Battashi, A., Al-Tamimi, A., Al-Mamari, K., Chutani, M. (2009). Design and Experimental Investigation of Portable Solar Thermoelectric Refrigerator. Renewable Energy, 34, 30-34.

[14] URL: http://www.cbc.ca/news/canada/thunder-bay/story/2013/01/22/tb y-thunder-bay-record-breaking-cold-temperatures.html,visited 10 July 2013. 


\section{Biographies}

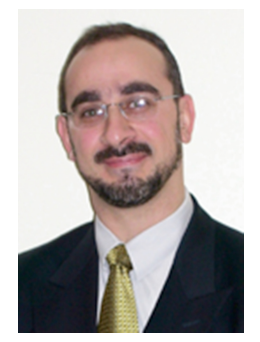

Dr. B. Ismail is currently an Associate professor at the Department of Mechanical Engineering, Lakehead University, Thunder Bay, Ontario, Canada. In 2004, Dr. Ismail earned his Ph.D. degree in Mechanical Engineering from McMaster University, Canada. Dr. Ismail's research activities are theoretical and applied in nature. Currently, his research areas of interest are focused on green engineering technologies related to alternative and renewable energy systems for power generation, heating and cooling. Also, Dr. Ismail has interest in other areas such as, energy efficiency, optimization of thermal and power systems, solar desalination, carbon-dioxide membrane gas separation for industrial emissions control and GHGs reduction, thermoelectrics, neutron radiography, and EGR cooling systems. Dr. Ismail has published many articles related to his research areas in reputable Journals and international conferences. During his research activities, Dr. Ismail has also supervised many graduate students and senior undergraduate students in Mechanical engineering with projects related to innovative green engineering technologies.

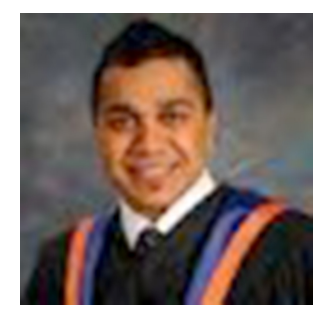

Mr. Alabdrabalnabi has recently obtained his M.Sc. degree in Control Engineering from Lakehead University in December 2013. His Master's thesis work was supervised by Dr. B. Ismail in the area of solar PV-powered thermoelectric heat pump systems with potential applications in Thunder Bay city, Northwestern Ontario, Canada. 